\title{
Comentarios
}

\section{El empantanamiento de la condonación de la deuda agraria}

Con la recomposición de la Asamblea Legislativa a partir de la segunda mitad de 1997, el tema de la condonación de la deuda agraria ha despertado nuevos y álgidos debates entre el partido de gobierno Alianza Republicana Nacionalista (ARENA), por un lado, y la oposición política y las organizaciones campesinas por el otro. El principal punto de discusión está centrado en sus posibles efectos. Los detractores de la condonación, fundamentalmente de ARENA, argumentan que ésta no conviene porque crearía un antecedente negativo para el agro salvadoreño y nefastos efectos sobre el ámbito institucional y económico. En cambio, para los apologistas de la condonación, ésta se perfila como una importante medida para la reactivación del sector agropecuario.

Esta discusión provocó ya un franco enfrentamiento entre los poderes ejecutivo y legislativo, y ha decantado en la aprobación, por parte de la oposición política, de dos dectetos de condonación que posteriormente serían vetados por el Presidente de la República, Armando Calderón Sol. Con estos hechos, la solución del problema de la deuda agraria ha entrado en un nuevo proceso de estancamiento que, por cierto, resulta muy perjudicial para la ya deteriorada situación económica del sector agropecuario. En lo que sigue, se trata de reseñar el surgimiento de la deuda agraria, examinar las dinámicas más recientes en torno al tema de su condonación y presentar algunas sugerencias para enfrentar este problema de una forma más coherente con la búsqueda del desarrollo del sector agropecuario, el cual es perseguido - a nivel de discur- so- por el mismo gobiemo que se opone a la condonación de la deuda agraria.

La deuda agraria surgió inicialmente como resultado de la implementación del proceso de reforma agraria de la década de 1980 , especialmente con la implementación de su primera fase. La deuda agraria consistía en el valor de las tierras que fueron expropiadas para ser entregadas a las cooperativas beneficiarias y que estas últimas adeudan al Estado. De acuerdo a la novena evaluación del proceso de reforma agraria, para 1990, el monto de la deuda agraria ascendía a cerca de 1,500 millones de colones, de lo cual la mayor parte era adeudado por las cooperativas de la primera fase de la reforma agraria. Actualmente, el concepto de deuda agraria se ha ampliado hasta incluir otros rubros que nada tienen que ver con la implementación de la reforma agraria.

De acuerdo a datos recientes, la deuda agraria ascendería a cerca de $3,741.8$ millones de colones, distribuidos así: 1,609.1 millones al Instituto de Transformación Agraria (ISTA), 1245.6 millones al Banco de Fomento Agropecuario (BFA) y 997.1 millones al Fondo Salvadoreño de Fortalecimiento Financiero (FOSAFFI). Cabe destacar que en el caso del BFA se incluyen 545 millones de colones que corresponden a la ejecución del Programa de Transferencia de Tierras contenido en los Acuerdos de $\mathrm{Paz}$ entre el gobiemo y la antigua guerrilla del FMLN firmados en 1992.

Así, puede señalarse que la deuda agraria original corresponde fundamentalmente a lo adeudado al 
Instituto Salvadoreño de Transformación Agraria, es decir, cerca de 43 por ciento del total de la deuda agraria. Los restantes componentes tienen orígenes diferentes. La deuda del Banco de Fomento Agropecuario corresponde, además del financiamiento de la transferencia de tierras, a créditos de avío otorgados, en la mayoría de casos, al sector campesino. La deuda del FOSAFFI, por otra parte, proviene fundamentalmente de la absorción de la cartera crediticia que antecedió a la reprivatización de la banca a inicios de la década de 1990.

Una parte del componente de la deuda agraria proviene no del valor de las

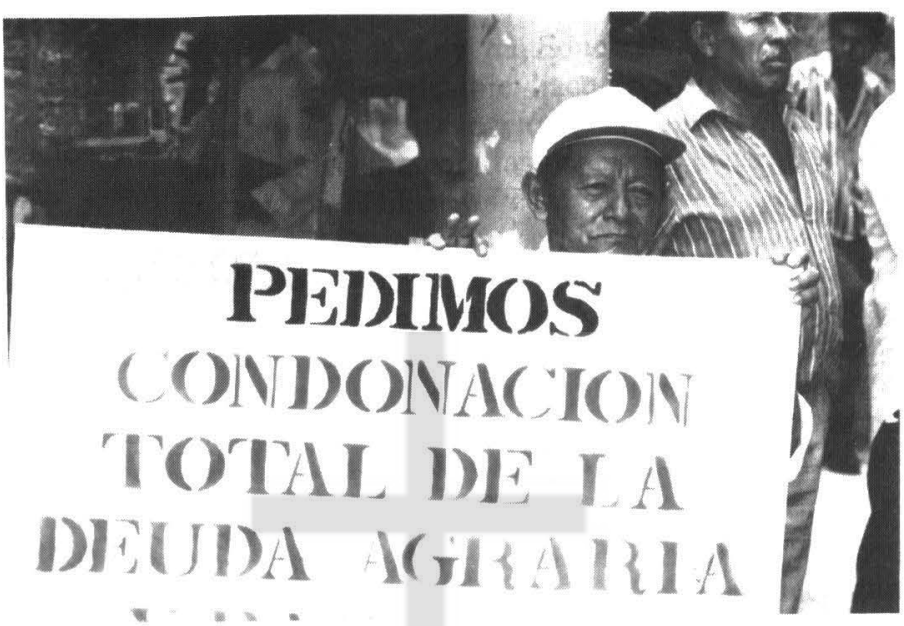
tierras, sino de la utilización de créditos de avío diferentes a los otorgados por el Banco de Fomento Agropecuario. Por ejemplo, la deuda del FOSAFFI tiene más que ver con la no recuperación de créditos otorgados por la banca privada a agricultores que, en muchos casos, nada tienen que ver con la reforma agraria.

Las discusiones en torno a la posibilidad de condonación de la deuda agraria resurgieron a partir de la llegada de la nueva Asamblea Legislativa, llegando a ocupar el primer plano dentro de los temas que se trataban a su interior. Las posturas de personeros del gobierno han estado claramente inclinadas hacia la no condonación de la deuda agraria. Inclusive, de acuerdo al Ministro de Hacienda, Enrique Hinds, la condonación de la deuda afectaría al sector financiero y desestimularía el otorgamiento de créditos; al mismo tiempo sostiene que tendría un impacto inicial en las finanzas públicas de aproximadamente 1,400 millones de colones. Como resultado, afirmó que se enfrentarían problemas de déficit fiscal, mayor inflación, deterioro de balanza de pagos, escasez de créditos, alzas en las tasas de interés, etc.

Las fracciones legislativas mayoritarias en la Asamblea Legislativa, por su parte, han mostrado una clara inclinación por proceder a la condonación de la deuda, aunque con diferentes enfoques. El Partido de Conciliación Nacional (PCN), por un lado, se inclina por condonar pequeñas deudas y cobrar grandes deudas que no fueron utilizadas para rubros agrícolas. El Frente Farabundo Martí para la Liberación Nacional (FMLN) se inclina por una condonación total de la deuda para estimular la reactivación del agro. El partido ARENA apoyaría

la condonación si ésta no supondría que los beneficiarios quedaran excluidos de la lista de personas sujetas de crédito.

Para el mes de noviembre de 1997, el tema de la condonación de la deuda agraria y bancaria conllevó importantes movimientos políticos, a saber: primero la aprobación, por parte de la Asamblea Legislativa, de dos decretos de condonación de la deuda agraria y, segundo, el subsiguiente veto presidencial invalidándolos debido a su supuesta inconstitucionalidad. Estos hechos han evidenciado nuevamente el conflicto de intereses que, en tomo a este punto, se ha desatado entre el partido de gobiemo y sus opositores. Es oportuno señalar aquí que, en buena medida, la oposición de ARENA a la condonación podría responder a un boicot de los proyectos políticos de su principal rival político, el FMLN. De hecho, como se reseña más adelante, ARENA ha cambiado su última postura de condonar hasta un 85 por ciento de la deuda hasta una de no condonarla.

El tema de la deuda agraria presenta, sin dudas, matices políticos, y ello se ha reflejado claramente en la confrontación que ha generado; sin embargo, de ser implementada selectivamente, también representaría un importante paso para la reactivación del sector agropecuario. En parte, el entrampamiento de la condonación se ha debido a que se ha reunido en un sólo grupo a diferentes tipos de deudores y de deuda, lo cual implica dar similar tratamiento a pequeños deudores beneficiarios de la reforma agraria, sin capacidad de pago, y a grandes deudores terratenientes con capacidad de pago, por ejemplo.

Después de un intenso debate legislativo en torno a la condonación de la deuda agraria y bancaria, 
esta fue aprobada por el pleno legislativo el pasado 30 de octubre. Mediante los decretos 135 y 136 se condonaron totalmente las deudas menores a los 500,000 colones y en un 93 por ciento las deudas que superaban esa cantidad. Este decreto fue apoyado principalmente por los partidos de oposición FMLN, Partido Demócrata Cristiano y PCN, no así por el partido ARENA. El principal argumento esgrimido por la oposición para apoyar la condonación total fue la necesidad de adoptar medidas que contribuyan a la recuperación económica del agro. Según éste planteamiento, la condonación de la deuda podría convertirse en un aliciente para la producción agropecuaria en la medida que liberaria de algunas obligaciones financieras al sector agropecuario.

El Presidente Armando Calderón Sol expresó, dos semanas después de aprobados, que su posición era de vetar los decretos 135 y 136 "por [resultar] inconstitucional e inconveniente". Según el Presidente, la condonación de la deuda es inconstitucional por "invadir la competencia del Órgano Judicial", pero principalmente porque se violenta "el Art. 232 de la Constitución, el cual prohíbe dispensar el pago de las deudas a favor del fisco o de los municipios".

En el mismo comunicado se agregan múltiples razones por las cuales los decretos resultan inconvenientes: "Por su falta de equidad; porque estimulan la indisciplina financiera por medio de la cultura de no pago; por su defectuosa y ambigua estructuración; por su grave efecto financiero y efecto inflacionario; porque darían lugar a reducir la inversión en infraestructura; por la pérdida de credibilidad del sector agropecuario como sujeto de crédito; porque se premia la ineficiencia y se castiga a quienes cumplen con sus compromisos; porque incorporan nuevos deudores no agropecuarios, en fin porque restan recursos a los programas de reactivación agropecuaria."

Los argumentos vertidos por una y otra parte para fundamentar sus posturas son, indistintamente, cuestionables. Los de los apologistas de la condonación porque fijan demasiadas expectativas en ésta y porque no diferencian adecuadamente entre los diferentes casos. La del Presidente porque adopta una postura ambigua y contradictoria frente al tema de la condonación que, incluso, llega a satanizarla. Sin embargo, ambas posturas tienen puntos rescatables.
Pretender, tal como lo hace la oposición en la Asamblea Legislativa, de que con el perdón de las deudas agropecuarias se obtendrá inmediatamente la recuperación del sector agropecuario es, en realidad, una postura ingenua. Los problemas del agro derivan, en gran medida, de su baja productividad y rentabilidad, a su vez resultado de factores ajenos al problema de la deuda tales como el agotamiento de los recursos naturales, los bajos precios, los bajos niveles de tecnificación, la atomización de la propiedad de la tierra, etc. Al examinar el problema de la condonación de la deuda no puede perderse de perspectiva el hecho de que, en realidad, la deuda agraria ha sido resultado de la profundización de la crisis económica en el agro, y la consecuente insolvencia financiera del sector. A su vez, la crisis del agro ha obedecido, últimamente, a las políticas económicas implementadas durante la década de 1990.

Aunque no trata de negarse que la condonación de la deuda puede ayudar a apuntalar un proceso de reactivación del agro, no puede dejar de mencionarse que ésta es sólo una de varias medidas necesarias.

Pretender condonar indistintamente las deudas de los agricultores podría implicar beneficiar a sectores con capacidad de pago y, en muchos casos, grandes terratenientes que han logrado diversificar su capital; sin embargo, no condonar implica cobrar deudas al sector beneficiario de la reforma agraria que fueron entregados en condiciones de desfavorables para la producción como la guerra y la baja productividad de las tierras asignadas. La reforma agraria tuvo una clara intencionalidad contrainsurgente, no de mejoramiento de la productividad agropecuaria, de hecho éste enfoque incluso provocó el fracaso financiero de algunos beneficiarios. Posteriormente, durante la década de 1990, el sector agropecuario en general ha debido sufrir el sesgo antiagropecuario de la política económica de ARENA y en ese contexto se ejecutó también la transferencia de tierras.

La postura de no condonación adoptada por el Presidente, por otra parte, refleja contradicciones en relación a la postura de su propio partido en torno a la condonación de la deuda e, incluso, en tomo al plan de desarrollo agropecuario que el mismo Presidente Calderón Sol ha propuesto. Anteriormente, ARENA ha aprobado decretos de condonación de un 70 por ciento de la deuda agraria, a cambio del pronto pago del restante 30 por ciento. Más tarde, 
el ex presidente de la República y actual presidente de ARENA, Alfredo Cristiani, presentó como una propuesta de su partido la condonación de hasta un 85 por ciento de la deuda agraria. Tildar de inconstitucional e inconveniente la condonación de la deuda implica aceptar que la propuesta inicial de ARENA también lo era.

Asimismo la postura presidencial entra en contradicción con ofrecimientos de programas de reactivación del agro presentados anteriormente. En su discurso presidencial de segundo año de gobierno el Presidente Calderón Sol ofreció "[poner] en marcha el plan integral de reactivación agropecuaria, cuyos puntos principales son: la seguridad jurídica en la propiedad de la tierra, crédito oportuno y preferente a las actividades agrícolas, suministro de tecnología e información de mercado, así como mejoras en la conservación de granos básicos...". Estas son precisamente algunas de las principales líneas de política definidas en el "Programa Agropecuario 1997" cuya implementación, a más de 15 meses después del primer ofrecimiento, aún no se concreta.

El ofrecimiento de otorgar "crédito oportuno y preferente" para el sector agropecuario ofrecido por el Presidente, se encuentra reñida con la posición de su gobierno de no condonar la mayor parte de la deuda agraria. Si se reconoce que el sector agropecuario no recibe crédito adecuado para incrementar su actividad económica, lo más consecuente es diseñar mecanismos para aliviar la carga financiera provocada por la deuda agraria; sin embargo, el gobiemo ha asumido una postura totalmente contraria a ello.

Adicionalmente, algunas de las razones presentadas por la Presidencia resultan cuestionables. Por ejemplo, la pérdida de credibilidad del sector agropecuario es un elemento que está presente en los criterios de asignación del crédito desde hace mucho tiempo. De otra forma, no habría crisis ni con- tracción del sector agropecuario. La cultura del no pago o indisciplina fiscal en realidad ya existe en el país y es practicada por los mismos sectores empresariales que retienen indebidamente el Impuesto al Valor Agregado o que ha sido favorecido con grandes exenciones de impuestos gracias a la reforma tributaria de ARENA.

Con todo, la propuesta de Calderón Sol ha colocado un importante valladar para la condonación de la deuda del sector reformado ya que, al declararla inconstitucional, ha cerrado la puerta para posibles propuestas alternativas, incluyendo la de condonación del 85 por ciento propuesta por la misma ARENA.

Lamentablemente, en la Asamblea Legislativa no se discriminó entre tipos de deuda y de deudores $y$, a final de cuentas, la propuesta de condonar totalmente ha provocado un entrampamiento aún mayor al que se enfrentaba antes. Por el momento, lo más razonable es profundizar adecuadamente en el estudio de casos y tipos de deuda para discriminar aún más y condonar solamente en aquellos casos en que se esté beneficiando a beneficiarios de la reforma agraria y transferencia de tierras, a los sectores campesinos y a pequeños productores. Ello contribuiría a construir alternativas de condonación de menor impacto económico y con mayores posibilidades de superar el veto presidencial.

Por el momento, es necesario que además de la condonación de la deuda se adopten medidas que prevengan un resurgimiento de este problema como resultante de la ya permanente crisis del sector agropecuario. Sin duda, se hará necesario que se contrarresten los efectos negativos de las políticas de liberalización económica implementadas por ARENA a lo largo de la década de 1990.

\section{Luis Ernesto Romano Martínez}

